\title{
Correction to: Sub-clinical thickening of the fovea in diabetes and its relationship to glycaemic control: a study using swept-source optical coherence tomography
}

\author{
Ross T. Aitchison ${ }^{1}$ (D) Graeme J. Kennedy ${ }^{1} \cdot$ Xinhua Shu $^{1} \cdot$ David C. Mansfield ${ }^{2} \cdot$ Uma Shahani $^{1}$ \\ Published online: 16 October 2020 \\ (C) Springer-Verlag GmbH Germany, part of Springer Nature 2020
}

\section{Correction to: Graefe's Archive for Clinical and Experimental Ophthalmology https://doi.org/10.1007/s00417-020-04914-2}

The published online version contains mistake on the top line of the third part of the equation. It should be: $27(\pi \mathrm{C} 1+\pi \mathrm{C} 2+$ $\pi \mathrm{C} 3+\pi \mathrm{C} 4)$. The $\pi \mathrm{C} 3$ seems to have been duplicated in the final version.

Publisher's note Springer Nature remains neutral with regard to jurisdictional claims in published maps and institutional affiliations.

The online version of the original article can be found at https://doi.org/ 10.1007/s00417-020-04914-2.

\footnotetext{
Ross T. Aitchison

ross.aitchison@gcu.ac.uk

$\triangle$ Uma Shahani

u.shahani@gcu.ac.uk

1 School of Health and Life Sciences, Glasgow Caledonian University, Glasgow, UK

2 Department of Ophthalmology, Inverclyde Royal Hospital, Greenock, UK
} 